Article

\title{
Bioactivity Behavior Evaluation of PCL-Chitosan-Nanobaghdadite Coating on AZ91 Magnesium Alloy in Simulated Body Fluid
}

\author{
Farzad Soleymani ${ }^{1}$, Rahmatollah Emadi ${ }^{2}$, Sorour Sadeghzade ${ }^{2,3}\left(\mathbb{D}\right.$ and Fariborz Tavangarian ${ }^{3, *}$ \\ 1 Materials Engineering Group, Pardis College, Isfahan University of Technology, Isfahan 84156-83111, Iran; \\ fsoleimani236@gmail.com \\ 2 Materials Research Group, Department of Materials Engineering, Isfahan University of Technology, \\ Isfahan 84156-83111, Iran; remadi@cc.iut.ac.ir \\ 3 Mechanical Engineering Program, School of Science, Engineering and Technology, Pennsylvania State \\ University, Harrisburg, Middletown, PA 17057, USA; soroursadeghzade@gmail.com or sxs2640@psu.edu \\ * Correspondence: fut16@psu.edu or f_tavangarian@yahoo.com; Tel.: +1-717-948-6125
}

Received: 8 February 2020; Accepted: 27 February 2020; Published: 3 March 2020

\begin{abstract}
Polymer-ceramic composite coatings on magnesium-based alloys have attracted lots of attention in recent years, to control the speed of degradability and to enhance bioactivity and biocompatibility. In this study, to decrease the corrosion rate in a simulated body fluid (SBF) solution for long periods, to control degradability, and to enhance bioactivity, polycaprolactone-chitosan composite coatings with different percentages of baghdadite ( $0 \mathrm{wt} . \%, 3 \mathrm{wt} . \%$, and $5 \mathrm{wt} . \%)$ were applied to an anodized AZ91 alloy. According to the results of the immersion test of the composite coating containing $3 \mathrm{wt}$ \% baghdadite in a phosphate buffer solution (PBS), the corrosion rate decreased from 0.45 (for the AZ91 sample) to $0.11 \mathrm{mg} / \mathrm{cm}^{2} \cdot \mathrm{h}$ after seven days of immersion. To evaluate the apatite formation capability of specimens, samples were immersed in an SBF solution. The results showed that the samples were bioactive as apatite layers formed on the surface of specimens. The composite coating containing $3 \mathrm{wt}$.\% baghdadite showed the highest apatite-formation capability, with a controlled release of ions, and the lowest corrosion rate in the SBF.
\end{abstract}

Keywords: polycaprolactone; Mg alloy; chitosan; baghdadite; coating

\section{Introduction}

Nowadays, metals have a wide range of applications in orthopedic and dental surgeries; however, only a few are biocompatible and being used as implants [1,2]. The most important metals are stainless steels, cobalt-, nickel-, magnesium-, and titanium-based alloys [3]. Among these metals, magnesium and its alloys have been used as temporary implants for biomedical and orthopedic applications due to close mechanical properties to those of bone, the release of magnesium ions inside the bone, and their biodegradability in the simulated body fluid (SBF) medium [4,5]. One of the main reasons for using magnesium alloys is that, over time, it degrades inside the body and is replaced with surrounding tissue and consequently eliminates the need for a second surgery [6,7]. On the other hand, these alloys have attracted great attention due to their high strength-to-weight ratios [7]. The main advantages of magnesium over other metallic biomaterials are its biodegradability and lightweight [8]. It is an essential element for the body's metabolic activities. However, its high corrosion rate causes the formation of cavities and porosities after implantation, which can negatively affect its mechanical and biological properties $[9,10]$. Many studies have been conducted on controlling the degradation rate of magnesium and its alloys for medical applications [11,12]. A new approach to increase the life of metal implants is to apply nanostructured coatings on their surfaces. For instance, applying 
silica-, phosphate-, and calcium phosphate-based ceramic coatings on magnesium-based alloys has been reported; however, after applying the ceramic coatings on the alloy, microcracks and porosities form, and pitting corrosion occurs [7,13-15]. Therefore, ceramic-polymer composite coatings have recently been used to overcome this problem [16]. In fact, applying polymer coatings can create a smooth surface that is free of any porosities $[16,17]$. In addition to their high mechanical properties, ceramic-polymer composite coatings form a structure with similar morphology to that of bone, which enhances bioactivity and biocompatibility of implants [17-19].

Polycaprolactone (PCL) is one of the extensively used polymers for biomedical applications. Iqbal at al. [20] showed that zinc-doped hydroxyapatite/zeolite/polycaprolactone (PCL) composite coatings on magnesium substrate could improve the corrosion resistance and antimicrobial properties against the E. coli bacteria. Azarudeen et al. [21] 3D-printed PCL/gelatin composite scaffolds for bone-tissue-engineering applications. The results showed improved hydrophilicity and more reactive sites for cell attachment in the scaffolds. Sadeghzade et al. [22] investigated the effects of PCL coating on diopside/baghdadite scaffolds. They found that modifying the ceramic scaffolds with $6 \mathrm{wt} . \%$ PCL polymer could control degradability and increase proliferation rate, attachment, and spreading of bone marrow-derived stem cells (BMSC). Chitosan is another biopolymer that has been the subject of many studies [23]. Chitosan showed antibacterial properties and has been used in various coatings, to control the degradation rate in biomedical applications [24-27]. Therefore, in many applications, a combination of these materials is needed to improve and adjust the properties of the final product. Based on our previous study [28], applying this polymer-ceramic composite coating on AZ91 alloy can be an effective method to control the degradation and bioactivity of the magnesium alloys for tissue-engineering applications. Moreover, it was found that the formation of a dense composite coating on the surface improved corrosion resistance and decreased corrosion rate of AZ91 substrate. The aim of this study was to evaluate the bioactivity and biodegradability of PCL-chitosan-nanobaghdadite coating on magnesium alloy (AZ91) substrate. For this purpose, the effect of baghdadite nanoparticles was evaluated on the biocorrosion behavior, bioactivity, and corrosion rate for different immersion times in an SBF solution.

\section{Materials and Methods}

\subsection{Nano-Baghdadite Fabrication}

In order to produce baghdadite nanopowder, zirconium oxynitrate, calcium nitrate, and tetraethyl orthosilicate (TEOS) (all from Sigma-Aldrich, St. Louis, MI, USA, 99\% purity) were used as raw materials with a stoichiometric ratio of 1:3:2. First, TEOS, ethanol, and nitric acid, with a molar ratio of 1:8:0.16, were mixed, using a magnetic stirrer, for $30 \mathrm{~min}$. Then, the raw materials were added to the solution, and the obtained slurry was stirred at room temperature for $5 \mathrm{~h}$. After that, the sol was dried at $60^{\circ} \mathrm{C}$ for one day, and then at $100^{\circ} \mathrm{C}$ for two days. The dried gel was then calcined at $1150{ }^{\circ} \mathrm{C}$ for $3 \mathrm{~h}$, followed by $2 \mathrm{~h}$ ball-milling process [29].

\subsection{Polymeric Coating Process on AZ91}

In order to improve the adhesion of the polymeric coating to the substrate, the electrolyte of micro-arc oxidation (MAO), with the composition of $100 \mathrm{~g}$ of $\mathrm{NaOH}$ and $100 \mathrm{~g}$ of $\mathrm{Na}_{2} \mathrm{SiO}_{3}$, was mixed in $1 \mathrm{~L}$ of distilled water. MAO was carried out at a voltage of $60 \mathrm{~V}$ for $30 \mathrm{~min}$ [10].

To create a polymer coating on the anodized samples of AZ91, $90 \mathrm{wt}$.\% of polycaprolactone (PCL) (molecular weight of 60,000, Sigma-Aldrich) and $10 \mathrm{wt} . \%$ of Chitosan (Ch) (molecular weight of 50,000, Sigma-Aldrich) were dissolved in a mixture of acetic acid and formic acid with a weight ratio of 3 to 1 [30]. Next, different percentages of baghdadite nanopowder ( $0 \mathrm{wt} . \%, 1 \mathrm{wt} . \%, 3 \mathrm{wt} . \%$, and $5 \mathrm{wt} . \%)$ were added to the polymer solution, and the solution was stirred for three hours. The coating operation was performed through the immersion method, at the entry and exit speeds of $6 \mathrm{~mm} / \mathrm{min}$, and for five times for each sample. Table 1 shows the designation of different samples. 
Table 1. The designation of various samples.

\begin{tabular}{cc}
\hline Designation & Process \\
\hline AZ91 & AZ91 Alloy \\
MAO & AZ91 alloy subjected to MAO process \\
$\mathrm{MAO} / \mathrm{P}$ & MAO coated with PCL/Chitosan polymer \\
$\mathrm{MAO} / \mathrm{P} / \mathrm{B}$ & $\mathrm{MAO}$ coated with $\mathrm{PCL} / \mathrm{Ch}-1 \%$ Baghdadite \\
$\mathrm{MAO} / \mathrm{P} / 3 \mathrm{~B}$ & $\mathrm{MAO}$ coated with $\mathrm{PCL} / \mathrm{Ch}-3 \%$ Baghdadite \\
$\mathrm{MAO} / \mathrm{P} / 5 \mathrm{~B}$ & $\mathrm{MAO}$ coated with $\mathrm{PCL} / \mathrm{Ch}-5 \%$ Baghdadite \\
\hline
\end{tabular}

\subsection{Evaluation of the Biocorrosion Behavior}

The simulated body fluid (SBF) was used to investigate the apatite formation ability of samples before and after the modification process, according to Bohner and Limatre's instructions [31]. Table 2 shows the composition of the SBF solution [32]. The samples were immersed in SBF ( $\mathrm{pH}=7.38)$ in Benn Mary bath, at $37^{\circ} \mathrm{C}$, for $7,14,21$, and 28 days. The $\mathrm{pH}$ changes of SBF solution for various samples were evaluated as a function of time. In order to evaluate the hydroxyl carbonate apatite (HCA), scanning electron microscopy (SEM, Philips XL30, Amsterdam, The Netherlands, with an acceleration voltage of $30 \mathrm{kV}$ ) was carried out. In addition, the energy-dispersive spectroscopy (EDS, Philips XL30, Amsterdam, The Netherlands) was used to investigate the functional groups of hydroxyl carbonate apatite (HCA).

Table 2. The ion concentrations of the SBF solution [32].

\begin{tabular}{cc}
\hline Ion & Ion Concentration (mM) \\
\hline $\mathrm{Na}^{+}$ & 142.0 \\
$\mathrm{~K}^{+}$ & 5.0 \\
$\mathrm{Mg}^{2+}$ & 1.5 \\
$\mathrm{Ca}^{2+}$ & 2.5 \\
$\mathrm{Cl}^{-}$ & 147.8 \\
$\mathrm{HCO}_{3}^{-}$ & 4.2 \\
$\mathrm{HPO}_{4}^{2-}$ & 1.0 \\
$\mathrm{SO}_{4}^{2-}$ & 0.5 \\
$\mathrm{pH}^{-}$ & 7.40 \\
\hline
\end{tabular}

In order to evaluate the degradability of samples, the buffered saline solution (PBS) (pH value 7.4 and Ben Mary bath temperature of $37^{\circ} \mathrm{C}$ ) was carried out for $7,14,21$, and 28 days [33]. In addition, the PBS solution was changed every 3 days. At the end of each time point, samples were removed from the buffer solution, and their weight loss was calculated.

The weight changes of samples were converted to corrosion rate, according to the following equation:

$$
C R=\frac{W}{A t}
$$

where $C R$ is the corrosion rate $(\mathrm{mg} / \mathrm{h}), W$ is the weight loss of samples $(\mathrm{mg}), A$ is the initial sample surface exposed to the corrosive environment $\left(\mathrm{cm}^{2}\right)$, and $t$ is the soaking time (h) [10].

\subsection{Characterization of Modified and Unmodified Samples}

Phase analysis of baghdadite powder was performed by using the X-ray diffraction (XRD) technique by Philips (Modle:PW1730, Philips, Amsterdam, The Netherlands), with $\mathrm{Cu}$ K $\alpha$ radiation $\lambda=0.154 \mathrm{~nm}, 20 \mathrm{kV}$ and $30 \mathrm{~mA}$, in the $2 \theta$ range of $20^{\circ}-70^{\circ}$ (step size $0.05^{\circ}$ and time per step $1 \mathrm{~s})$. The Williamson-Hall method [34] was used to estimate the crystallite size of the baghdadite powder. Scanning electron microscopy (SEM) (Philips XL30, an acceleration voltage of $30 \mathrm{kV}$ ) and energy-dispersive spectroscopy (EDS) were used to investigate the modified and unmodified samples. 
The powder morphology and size were investigated by a transmission electron microscope (TEM) (TEM, Philips, EM208S). The applied voltage was $100 \mathrm{kV}$, and ImageJ software was used to measure the baghdadite crystallites' size.

The wettability test was carried out, using an angle finder, in order to investigate the effect of baghdadite nanoparticles on the hydrophilic or hydrophobic behavior of the applied polymer coating on the AZ91 samples [19]. In each of the tests, a droplet of $2 \mu \mathrm{L}$ (water) was laid on the surface of the samples, using a DragonLab StepMate stepper (model: JV62782, DragonLab, Beijing, China). The average wettability angle was reported, using ImageJ software (version 1.52q). In order to examine the surface roughness before and after coating, a Mitutoyo roughness meter (Model: SJ-210, Grainger, Chicago, IL, USA) was used, and the mean surface roughness (Ra) was reported [19,28].

\section{Results and Discussions}

Figure 1a shows the TEM image of the produced baghdadite nanoparticles. As can be seen, baghdadite nanoparticles had nearly spherical shapes. Figure $1 \mathrm{~b}$ shows the XRD pattern of baghdadite nanopowder. In this pattern, peaks resulting from the produced powder were in a perfect agreement with the standard baghdadite card (JCPDS 00-047-1854). The size of baghdadite crystallites calculated by the Williamson-Hall method was about $61 \pm 3 \mathrm{~nm}$.

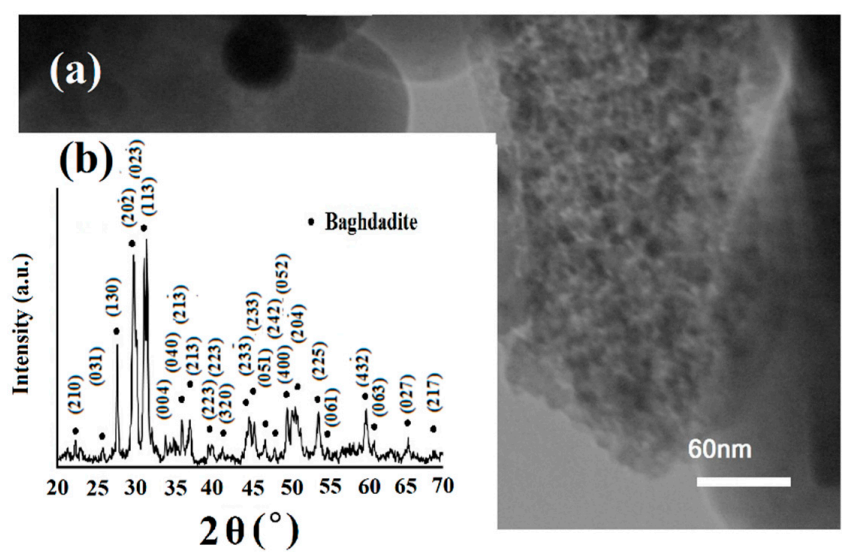

Figure 1. (a) TEM micrograph and (b) XRD patterns of baghdadite nanopowder fabricated by sol-gel technique.

Figure 2a-f shows SEM and EDS images of the AZ91 and MAO samples, as well as the sample coated with PCL-Ch- $5 \mathrm{wt} . \%$ baghdadite after the corrosion test. According to these images, the uncoated specimen has been affected by pitting corrosion on its entire surface, whereas applying the MAO coating and the polymer-ceramic composite coating on AZ91 reduced the number of cracks and cavities on the surfaces. In fact, coatings acted as a protective layer between the substrate and the electrolyte. When exposed to corrosive media containing $\mathrm{Cl}^{-}$, magnesium alloys were corroded, and the corrosion product, $\mathrm{Mg}(\mathrm{OH})_{2}$, was deposited on the surface (presence of sediments on the corroded area) [35]. The EDS results corresponding to the AZ91 sample (Figure 2b) demonstrated the presence of elements such as $\mathrm{Mg}, \mathrm{Al}, \mathrm{O}, \mathrm{Cl}$, and $\mathrm{Na}$. The presence of $\mathrm{Mg}$ and $\mathrm{O}$ indicated the formation of corrosion products $\left(\mathrm{Mg}(\mathrm{OH})_{2}\right)$ and a small amount of magnesium oxide on the surface. The presence of $\mathrm{Al}$ was associated with the AZ91 sample, and the presence of chlorine and sodium on the surface was the result of the exposure to the SBF solution and their deposition on the surface. Pitting corrosion was not observed in the specimen containing $5 \mathrm{wt}$.\% baghdadite nanoparticles in its coating. Only some cracks were detected in some parts of the coating after $2 \mathrm{~h}$ of corrosion testing. In this specimen, the presence of $\mathrm{Ca}, \mathrm{Si}$, and $\mathrm{Zr}$ ions on the surface of the coating was combined with the phosphate in the electrolyte to produce calcium-phosphate compounds, which were deposited on the surface, thus improved the corrosion resistance of this specimen. Furthermore, the formation of these compounds on the surface improved bioactivity. According to the EDS results of the MAO sample, the presence of $\mathrm{Si}$ 
indicated the formation of forsterite as a result of applying a micro-spark coating on the magnesium oxide substrate (Figure 2e). As seen, the percentage of magnesium decreased compared to that of the AZ91 sample, indicating a reduction in the corrosion rate. By applying the polymer-ceramic coating, the corrosion rate further decreased, the amount of magnesium on the surface decreased, and a peak resulting from phosphorus appeared (Figure 2f), indicating the deposition of phosphate groups on the surface. The SEM images of the surfaces of modified and unmodified samples coated with different composites were shown in our previous study [28]. The MgO layer and forsterite particles on the surface of AZ91 alloy play a protective role, improving the bioactivity of alloy, and can act as an intermediate layer for better adhesion of the coating to the substrate. As shown in [28], a smooth and uniform layer on the surface of MAO was observed as a result of applying the PCL/chitosan polymer coating. An increase in the roughness of the specimens was observed as a result of adding different amounts of baghdadite powder.
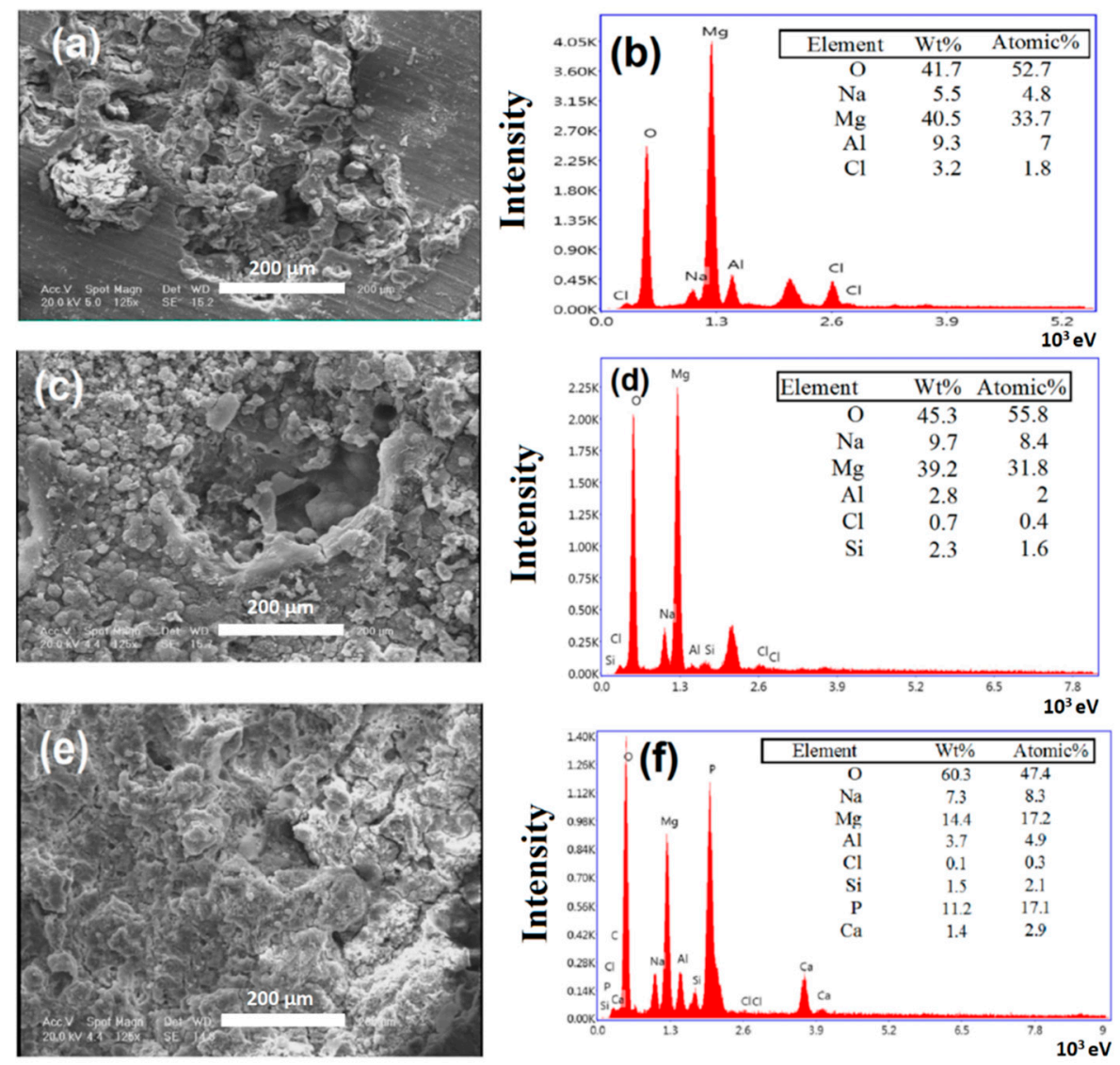

Figure 2. SEM images of (a) AZ91, (c) MAO, (e) MAO/P/5Ba, and EDS spectra of (b) AZ91, (d) MAO, and (f) $\mathrm{MAO} / \mathrm{P} / 5 \mathrm{~B}$, after corrosion test in $\mathrm{SBF}$ for $30 \mathrm{~min}$.

Figures 3 and 4 show SEM images and EDS results of MAO, MAO/P, MAO/P/1B, MAO/P/3B, and $\mathrm{MAO} / \mathrm{P} / 5 \mathrm{~B}$ after 7 and 28 days of immersion in an SBF solution, respectively. A sedimentary layer, which was expected to be the same bonelike apatite, was observed on the samples. With the application of MAO coating on the surface of the AZ91 sample, corrosion resistance increased, and the pitting corrosion rate decreased.

The results of the EDS test on the MAO sample after seven days of immersion in the SBF solution (Figure 3c) indicated that a small number of calcium-phosphate compounds formed on the surface of the sample. The presence of high amounts of $\mathrm{Mg}$ and $\mathrm{O}$ on the surface was evidence of the presence of corrosion products and magnesium oxide, in addition to calcium-phosphate compounds. 
The presence of chloride ions in the SBF solution damaged the oxide and hydroxide layers on the surface of the anodized AZ91 alloy and subsequently led to the formation of cavities on the surface, thus resulting in the corrosion of the substrate [11]. As a result, the degradability resistance of the magnesium-based alloy decreased in the SBF medium, thus reducing the total resistance of the implant [36]. Consequently, using this implant in the body will result in the death of the surrounding tissue due to the high release rate of magnesium ions and magnesium hydroxide compounds inside the body. As mentioned, magnesium hydroxide compounds resulting from the corrosion of the substrate were not stable and decomposed in the presence of chlorine [35]. Therefore, they could not act as a protective layer.
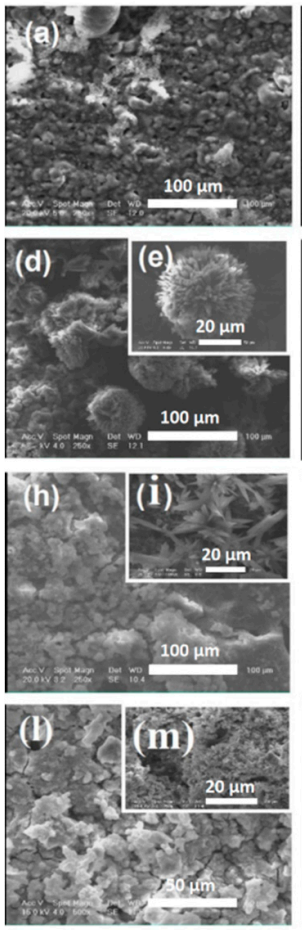
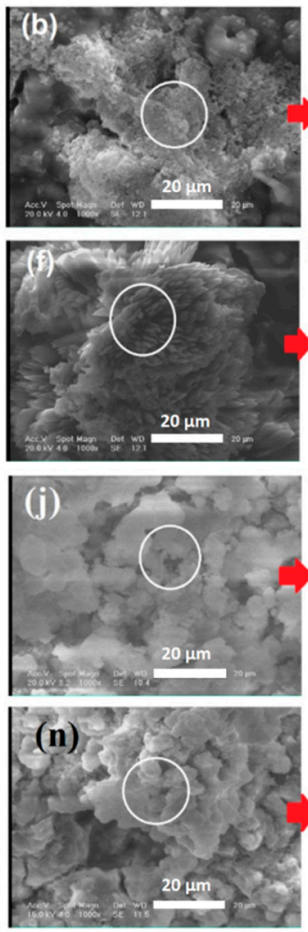
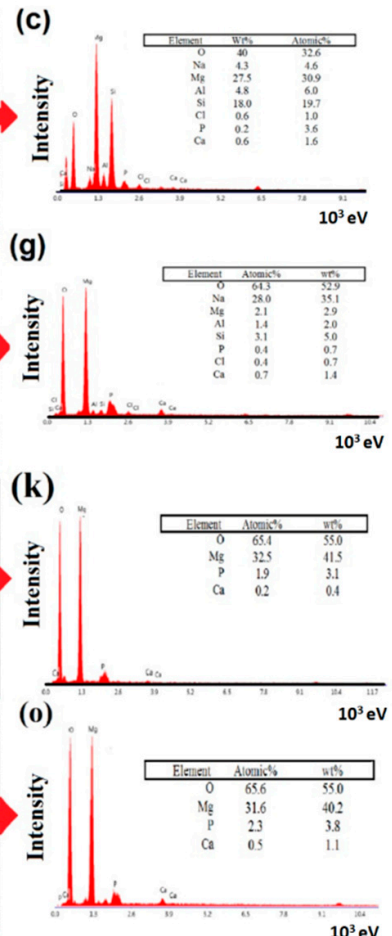

Figure 3. SEM images of $(\mathbf{a}, \mathbf{b}) \mathrm{MAO},(\mathbf{d}-\mathbf{f}) \mathrm{MAO} / \mathrm{P},(\mathbf{h}-\mathbf{j}) \mathrm{MAO} / \mathrm{P} / 3 \mathrm{~B},(\mathbf{l}-\mathbf{n}) \mathrm{MAO} / \mathrm{P} / 5 \mathrm{~B}$, and EDS spectra of (c) MAO, (g) MAO/P, (k) MAO/P/3B, and (o) MAO/P/5B after seven days of immersion in SBF.
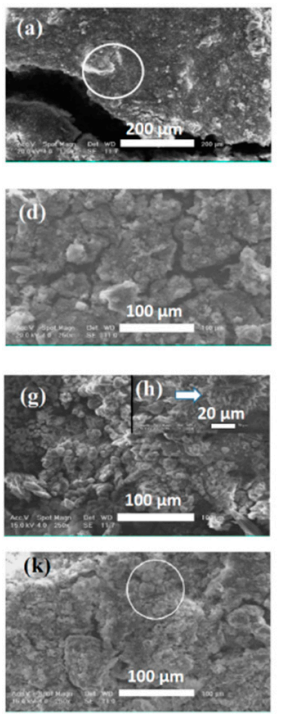
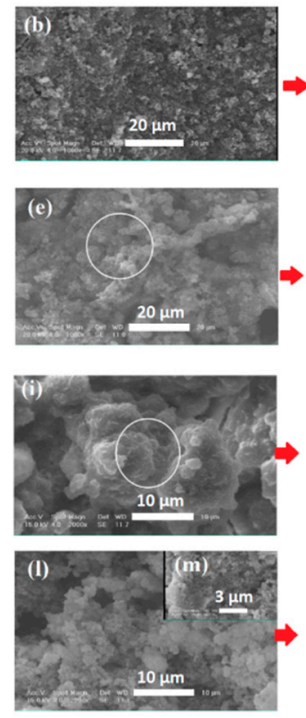
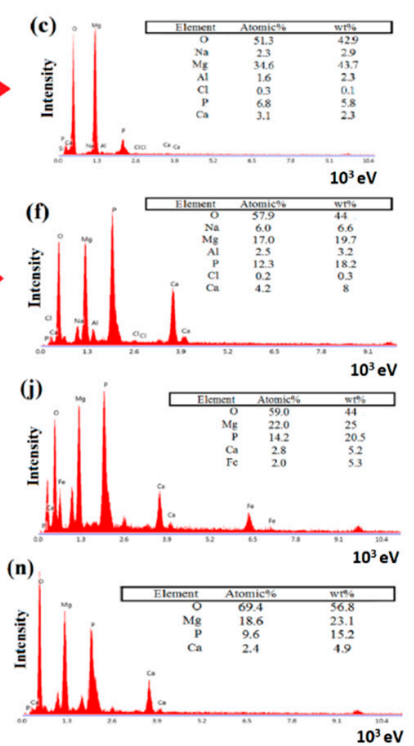

Figure 4. SEM images of (a,b) $\mathrm{MAO},(\mathbf{d}, \mathbf{e}) \mathrm{MAO} / \mathrm{P},(\mathbf{g}-\mathbf{i}) \mathrm{MAO} / \mathrm{P} / 3 \mathrm{~B},(\mathbf{k}-\mathbf{m}) \mathrm{MAO} / \mathrm{P} / 5 \mathrm{~B}$, and $\mathrm{EDS}$ spectra of (c) $\mathrm{MAO},(\mathbf{f}) \mathrm{MAO} / \mathrm{P},(\mathbf{j}) \mathrm{MAO} / \mathrm{P} / 3 \mathrm{~B}$, and (n) $\mathrm{MAO} / \mathrm{P} / 5 \mathrm{~B}$ after 28 days of immersion in $\mathrm{SBF}$. 
Applying a polymer coating along with ceramic reinforcement particles increases the formation capability of calcium-phosphate compounds on the surface and controls the degradability rate of magnesium alloys [8]. In similar works carried out by researchers, it has been pointed out that formation of calcium-phosphate compounds on the surface of magnesium implants could greatly reduce their degradability rate, because these compounds are greatly resistant and stable in a medium containing chloride ions and are not easily degraded, unlike the magnesium hydroxide layer [10]. Therefore, they can control the degradability rate, greatly reduce the corrosion rate, improve the bonding between the implant and tissue, and stabilize the implant in the body.

As the SEM images of the MAO/P sample show (Figure $3 \mathrm{~d}-\mathrm{f}$ ), applying this polymer-ceramic coating reduced the number of attacks on the alloy's surface. The number of surface cavities and cracks decreased, and the rate of the formation of calcium-phosphate compounds with the cauliflower morphology increased. These findings were in good agreement with the results of the EDS. In addition, by referring to Figure $3 a, c$, it was found that the bioactivity of the surface enhanced, and a larger amount of apatite formed on the surface compared to the anodized sample, acting as further potential proof for the reduced corrosion rate on the surface.

The SEM images corresponding to the MAO/P/3B (Figure 3h-j) and MAO/P/5 B (Figure 31-n) samples indicated the formation of a larger amount of apatite on the surface. It can be ascribed to the presence of baghdadite ceramic particles in the coating. Baghdadite has high biocompatibility, bioactivity, and ion-release capability, as well as better mechanical properties compared to calcium-phosphate compounds [29,37]. It was found that baghdadite supports the growth, adhesion, and differentiation of osteoblast and osteoclast cells [38]. By comparing the EDS results of specimens with polymer coatings containing 3 (Figure 3k) and $5 \mathrm{wt} . \%$ (Figure 3o) baghdadite, it was found that the addition of a higher amount of baghdadite did not promote the formation of apatite on the surface of AZ91 magnesium alloy. Increasing the soaking time of the specimens in the SBF solution up to 28 days caused the formation of a larger amount of apatite on the surface compared to the samples soaked for seven days. This can be considered to be additional proof for the reduced corrosion rate on the surface. By comparing the EDS results of the specimens soaked for 7 and 28 days in SBF, it was found that, by increasing the soaking time, the formation of calcium-phosphate increased on the surface of the specimens. It can also be observed that the formation of apatite on the surface of $\mathrm{MAO}$ is 3.5 times lower than that of $\mathrm{MAO} / \mathrm{P} / 3 \mathrm{~B}$.

Figure 5 shows the corrosion rate, as well as weight loss of different samples. In addition, the surface roughness and wettability of modified and unmodified samples are shown in Figure 6. As can be seen in Figure 4, the specimen containing $1 \mathrm{wt} . \%$ and $5 \mathrm{wt} . \%$ baghdadite showed a higher corrosion rate compared to the coating containing $3 \mathrm{wt} . \%$ baghdadite, and this difference can be attributed to the roughness and hydrophilicity of the surface (Figure 6). In fact, adding a larger amount of baghdadite increased defects in the coating, while the surface became more hydrophilic; thus, the corrosion rate slightly increased relative to the specimen containing $3 \mathrm{wt}$.\% baghdadite. In fact, the cause of corrosion in the coated specimens was the penetration of the SBF into the coating through the defects, which results in corrosion of the substrate, but applying a polymer coating with reinforcing particles greatly reduced this problem. However, increasing the amount of these particles above an optimal level increased the defects, which directly affected the corrosion rate.

In addition, as can be observed in the SEM images, the morphology of apatite on the MAO specimen was different from that of the specimens with polymer coatings and/or polymer-baghdadite composite coatings. The apatite, forming on the MAO specimen, was almost spherical, whereas applying the polymer and composite coatings changed the apatite morphology into cauliflower and blade-like morphologies. Bonelike apatite possesses a blade-like morphology [31]. Therefore, the application of a polymer-ceramic coating on specimens containing magnesium led to the formation of apatite with a blade-like morphology, which was much closer to the structure of apatite in the bone tissue. Hence, this implant with the polymer-ceramic coating may provide better bonding to bone tissue. 

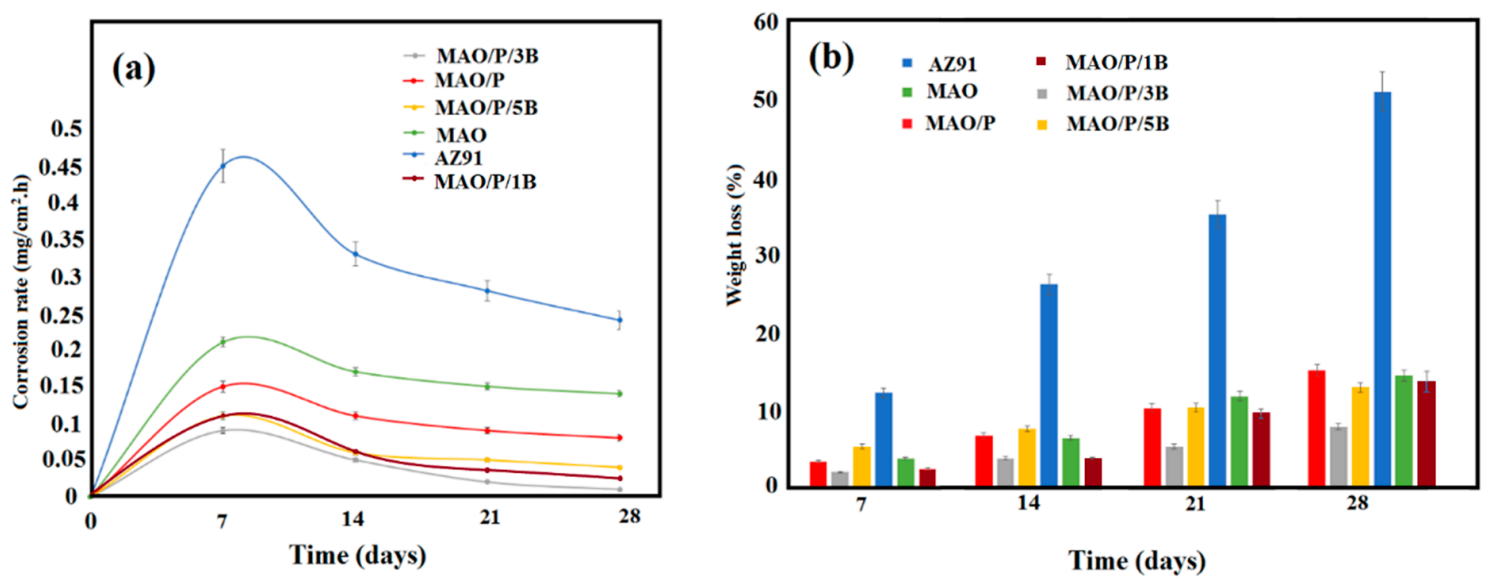

Figure 5. (a) Corrosion rate and (b) weight loss of samples after different soaking times in PBS.

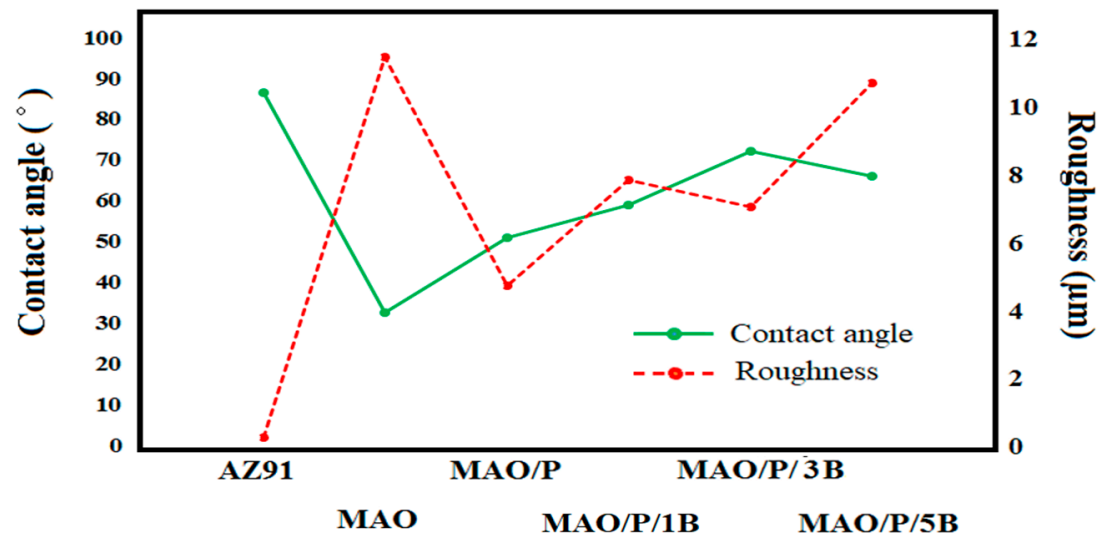

Figure 6. The average surface roughness and wettability of modified and unmodified samples.

An immersion test in the PBS solution was carried out in order to study the corrosion behavior of metallic alloys over a long period of time. In order to correctly calculate the corrosion rate and weight loss, first, all the specimens were washed in chromic acid (in order to wash corrosion products off the surfaces of the specimens) and then dried and weighed.

AZ91 sample showed the highest degree of weight loss in all immersion times, compared to the other specimens (Figure $5 \mathrm{~b}$ ). As seen, the uncoated magnesium specimen lost $50 \%$ of its weight after 28 days of immersion, whereas, anodizing the AZ91 sample led to a dramatic decrease in the weight loss in all immersion times. The specimens with the MAO coating showed a decrease of approximately $14 \%$ in its weight.

Applying the polymer and the polymer-ceramic coatings reduced the degradability rate of the anodized magnesium-based specimen to $15.08 \%, 7.82 \%$, and $12.87 \%$. The specimen containing $1 \mathrm{wt} . \%$ and $3 \mathrm{wt} . \%$ baghdadite showed the lowest degradability rate. The corrosion rates of different specimens were calculated by using the weight loss of the specimens before and after the immersion. As shown in Figure 5a, the AZ91 sample had the highest corrosion rate. The calculated corrosion rate for AZ91, $\mathrm{MAO}, \mathrm{MAO} / \mathrm{P}, \mathrm{MAO} / \mathrm{P} / 1 \mathrm{~B}, \mathrm{MAO} / \mathrm{P} / 3 \mathrm{~B}$, and $\mathrm{MAO} / \mathrm{P} / 5 \mathrm{~B}$ specimens after seven days of immersion were $0.45,0.21,0.15,0.1,0.09$, and $0.11 \mathrm{mg} / \mathrm{cm}^{2} \cdot \mathrm{h}$, respectively. As can be seen, after 14 days of immersion, the corrosion rates of all specimens sharply decreased, and this downward trend continued for up to 28 days of immersion. The most important reason for this trend could be the presence of corrosion products on the surface of the specimens, which to some extent reduced the corrosion rate over longer periods of immersion time [10]. As can be seen, the corrosion rate of AZ91, MAO, MAO/P, MAO/P/1B, $\mathrm{MAO} / \mathrm{P} / 3 \mathrm{~B}$, and $\mathrm{MAO} / \mathrm{P} / 5 \mathrm{~B}$ specimens after 28 days of immersion were found to be $0.24,0.14,0.08$, $0.03,0.01$, and $0.04 \mathrm{mg} / \mathrm{cm}^{2} \cdot \mathrm{h}$. 
Figure 7a shows the results of $\mathrm{pH}$ changes in the various samples for different immersion times. As seen in the AZ91 sample before coating, the highest degree of ion release occurred on the first day of immersion, such that the $\mathrm{pH}$ increased from 7.4 to 8.1 , and this upward trend continued until day seven (9.24), followed by a decrease in the $\mathrm{pH}$ afterward. The release of ions from the magnesium substrate was reduced in MAO and coated samples, which controlled the $\mathrm{pH}$ in the SBF medium. In fact, applying the polymer coating affected the biological behavior of the material and reduced the degradability of the magnesium specimen. In a biological medium, $\mathrm{pH}$ changes are very important and affect cell growth and cell proliferation. Extreme $\mathrm{pH}$ changes will result in cell death and will even lead to tissue loss under severe conditions $[9,18,33,39,40]$. Therefore, it is of great importance to control the $\mathrm{pH}$ and degradability of this type of implant. Applying the polymer coating decreased the $\mathrm{pH}$ changes in magnesium specimens. By increasing the immersion time, the polymer coating degraded and the release of ions and the $\mathrm{pH}$ increased; however, the $\mathrm{pH}$ changes were less than those in the specimen before coating. From among all the specimens, those containing $3 \mathrm{wt} . \%$ and $5 \mathrm{wt} . \%$ baghdadite experienced similar trends in terms of $\mathrm{pH}$ changes. In both of these specimens, apatite germination took about five days to occur on the surface, whereas in the AZ91 and MAO specimens and the specimen with the polymer coating, the starting point for a decrease in the $\mathrm{pH}$ value, which was generally attributed to apatite germination, increased to 7, 9, and 14 days. The reason for such behavior was merely the presence of baghdadite particles in the coating, which increased the bioactivity in the applied coating.

In specimens without baghdadite particles, the increase and decrease of the $\mathrm{pH}$ were due to the release of magnesium ions from the specimen and its ion exchange with the SBF. In fact, $\mathrm{pH}$ increased as magnesium ions were released from the surface of the specimen into the solution, and then decreased as a result of the deposition of corrosion products on the surface and consumption of $(\mathrm{OH}-)$ in the SBF solution (the same trend can be observed for the MAO/P/1B samples). However, in the specimens containing baghdadite particles ( $3 \mathrm{wt} . \%$ and $5 \mathrm{wt} . \%$ ), increased $\mathrm{pH}$ values, on the first days, could be ascribed to the breakdown of Si-O-Si bonds and the release of ions such as $\mathrm{Ca}^{2+}, \mathrm{Zr}^{4+}, \mathrm{Mg}^{2+}$, and $\mathrm{Si}^{4+}$ and their exchange with $\mathrm{H}^{+}$in SBF medium [31,33,34,41]. As shown in previous studies, this ion exchange leads to the formation of a silanol group on the surface of implants. Afterward, phosphate groups and calcium ions are adsorbed and deposited on the implant surface in the form of calcium-phosphate compounds [42,43]. This stage of apatite formation reduces the $\mathrm{pH}$ value in the solution. Subsequently, by creating a layer of apatite at the interface, these materials accelerate the growth and restoration of the tissue.
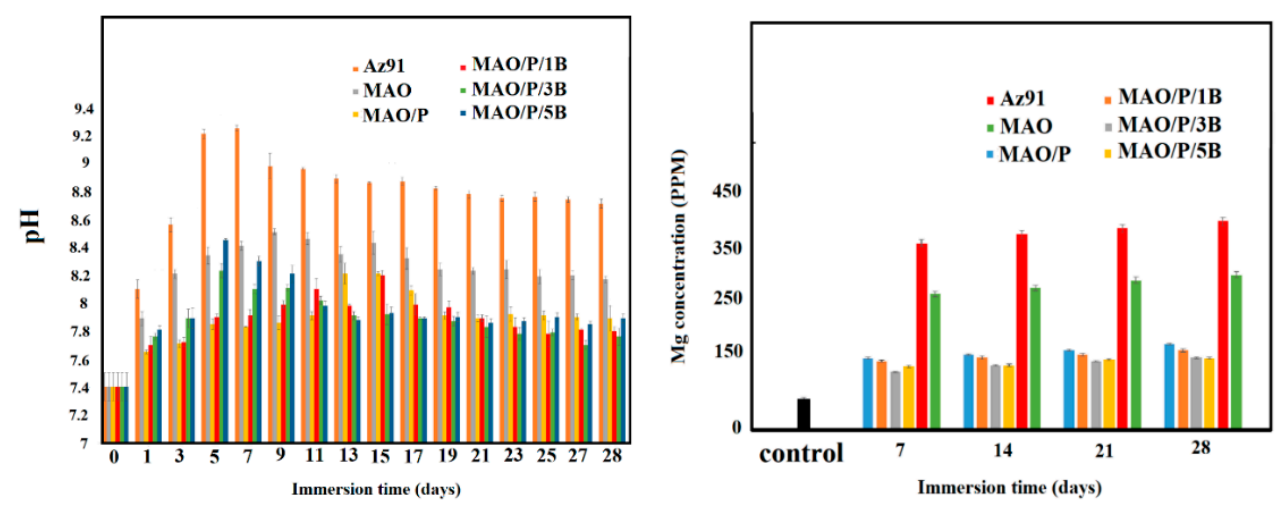

Figure 7. (a) pH changes and (b) Mg ion concentration of samples as a function of various soaking times.

Figure $7 \mathrm{~b}$ shows the changes of magnesium ions in different specimens for different immersion times. As can be seen in Figure $7 \mathrm{~b}$, the highest release of magnesium ions belonged to the AZ91 sample. After applying an MAO coating on the AZ91 sample, the release of magnesium ions decreased by $30 \%$. Furthermore, applying the polymer and polymer-ceramic coatings reduced the release of magnesium ions in the SBF solution by nearly $60 \%-70 \%$. The difference in the release of magnesium 
ions in $\mathrm{MAO} / \mathrm{P} / 3 \mathrm{~B}$ and $\mathrm{AZ91}$ samples was the maximum and can be ascribed to the consumption of magnesium ions in the solution and creation of corrosion products in $\mathrm{MAO} / \mathrm{P} / 3 \mathrm{~B}$. In fact, in the AZ91 specimen, the release of magnesium ions is so high and fast that there is no balance between the release of these ions in the solution and deposition of corrosion products and/or calcium-phosphate compounds on the surface. In other words, the release of magnesium ions in the solution was much higher than the deposition of corrosion products on the surface; the balance between the release of ions and the deposition of corrosion products was maintained through applying a polymer-ceramic coating on the surface. Thus, the release of magnesium ions in the solution sharply decreased.

It is worth noting that the highest release of magnesium ions occurred during the first seven days of immersion, and afterward, it decreased due to the deposition of corrosion products on the surface. This trend was observed in all the specimens.

According to the results of corrosion rates during long periods of immersion time, and through investigating the apatite-formation capability on the surface of different specimens and ion and $\mathrm{pH}$ changes in the SBF solution, it can be concluded that the specimen with the coating containing $3 \mathrm{wt} . \%$ baghdadite was the most suitable sample and might be a good candidate for tissue engineering applications.

\section{Conclusions}

In this study, a nanocomposite coating made of polycaprolactone-chitosan-baghdadite was successfully applied to an anodized AZ91 alloy, through an immersion method. The results obtained after one hour of the corrosion test indicated a reduced tendency of the alloy, coated with the composite coating, to pitting corrosion. In addition, the corrosion rate, calculated from the results of the immersion test in a phosphate buffer solution, indicated that addition of $3 \mathrm{wt} . \%$ baghdadite to the coating reduced the corrosion rate from 0.45 to $0.11 \mathrm{mg} / \mathrm{cm}^{2} \cdot \mathrm{h}$ after seven days of immersion, and from 0.24 to $0.04 \mathrm{mg} / \mathrm{cm}^{2} \cdot \mathrm{h}$ after 28 days of immersion. The controlled release of $\mathrm{Mg}$ ions in the SBF solution in different immersion times, the weight-loss changes, the controlled $\mathrm{pH}$ changes, and the improved bioactivity of the specimen with the composite coating containing $3 \mathrm{wt} . \%$ baghdadite, all indicate that applying this coating can improve the behavior of the AZ91 alloy, in order to be used in medical implants.

Author Contributions: Investigation, F.S. and S.S.; methodology, F.S. and S.S.; project administration, R.E. and F.T.; resources, R.E. and F.T.; supervision, R.E. and F.T.; writing-original draft, F.S. and S.S.; writing-review and editing, R.E. and F.T. All authors have read and agreed to the published version of the manuscript.

Funding: This research received no external funding.

Conflicts of Interest: The authors declare no conflict of interest.

\section{References}

1. Buford, A.; Goswami, T. Review of wear mechanisms in hip implants: Paper I-General. Mater. Des. 2004, 25, 385-393. [CrossRef]

2. Saini, M.; Singh, Y.; Arora, P.; Arora, V.; Jain, K. Implant biomaterials: A comprehensive review. World J. Clin. Cases WJCC 2015, 3, 52. [CrossRef] [PubMed]

3. Katti, K.S. Biomaterials in total joint replacement. Colloids Surf. B Biointerfaces 2004, 39, 133-142. [CrossRef] [PubMed]

4. Ren, Y.; Babaie, E.; Bhaduri, S.B. Nanostructured amorphous magnesium phosphate/poly (lactic acid) composite coating for enhanced corrosion resistance and bioactivity of biodegradable AZ31 magnesium alloy. Prog. Org. Coat. 2018, 118, 1-8. [CrossRef]

5. Ren, Y.; Zhou, H.; Nabiyouni, M.; Bhaduri, S.B. Rapid coating of AZ31 magnesium alloy with calcium deficient hydroxyapatite using microwave energy. Mater. Sci. Eng. C 2015, 49, 364-372. [CrossRef] [PubMed]

6. Zhao, Y.-B.; Liu, H.-P.; Li, C.-Y.; Chen, Y.; Li, S.-Q.; Zeng, R.-C.; Wang, Z.-L. Corrosion resistance and adhesion strength of a spin-assisted layer-by-layer assembled coating on AZ31 magnesium alloy. Appl. Surf. Sci. 2018, 434, 787-795. [CrossRef] 
7. Staiger, M.P.; Pietak, A.M.; Huadmai, J.; Dias, G. Magnesium and its alloys as orthopedic biomaterials: A review. Biomaterials 2006, 27, 1728-1734. [CrossRef]

8. Hornberger, H.; Virtanen, S.; Boccaccini, A.R. Biomedical coatings on magnesium alloys-A review. Acta Biomater. 2012, 8, 2442-2455. [CrossRef]

9. Diba, M.; Goudouri, O.-M.; Tapia, F.; Boccaccini, A.R. Magnesium-containing bioactive polycrystalline silicate-based ceramics and glass-ceramics for biomedical applications. Curr. Opin. Solid State Mater. Sci. 2014, 18, 147-167. [CrossRef]

10. Razavi, M.; Fathi, M.; Savabi, O.; Razavi, S.M.; Beni, B.H.; Vashaee, D.; Tayebi, L. Controlling the degradation rate of bioactive magnesium implants by electrophoretic deposition of akermanite coating. Ceram. Int. 2014, 40, 3865-3872. [CrossRef]

11. Xu, W.; Yagoshi, K.; Koga, Y.; Sasaki, M.; Niidome, T. Optimized polymer coating for magnesium alloy-based bioresorbable scaffolds for long-lasting drug release and corrosion resistance. Colloids Surf. B Biointerfaces 2018, 163, 100-106. [CrossRef]

12. Hu, R.-G.; Zhang, S.; Bu, J.-F.; Lin, C.-J.; Song, G.-L. Recent progress in corrosion protection of magnesium alloys by organic coatings. Prog. Org. Coat. 2012, 73, 129-141. [CrossRef]

13. Jin, T.; Wang, Y.; Yin, H.; Hao, X. Corrosion protection properties and mechanism of epoxy/acetic acid-doped polyaniline coating on magnesium alloy. J. Nanosci. Nanotechnol. 2018, 18, 4992-5000. [CrossRef]

14. Cui, L.-Y.; Gao, S.-D.; Li, P.-P.; Zeng, R.-C.; Zhang, F.; Li, S.-Q.; Han, E.-H. Corrosion resistance of a self-healing micro-arc oxidation/polymethyltrimethoxysilane composite coating on magnesium alloy AZ31. Corros. Sci. 2017, 118, 84-95. [CrossRef]

15. Sowmya, S.; Bumgardener, J.D.; Chennazhi, K.P.; Nair, S.V.; Jayakumar, R. Role of nanostructured biopolymers and bioceramics in enamel, dentin and periodontal tissue regeneration. Prog. Polym. Sci. 2013, 38, 1748-1772. [CrossRef]

16. Pozzo, L.D.Y.; da Conceição, T.F.; Spinelli, A.; Scharnagl, N.; Pires, A.T.N. Chitosan coatings crosslinked with genipin for corrosion protection of AZ31 magnesium alloy sheets. Carbohydr. Polym. 2018, 181, 71-77. [CrossRef]

17. Golshirazi, A.; Kharaziha, M.; Golozar, M.A. Polyethylenimine/kappa carrageenan: Micro-arc oxidation coating for passivation of magnesium alloy. Carbohydr. Polym. 2017, 167, 185-195. [CrossRef]

18. Sadeghzade, S.; Emadi, R.; Soleimani, B.; Tavangarian, F. Two-step modification process to improve mechanical properties and bioactivity of hydroxyfluorapatite scaffolds. Ceram. Int. 2018, 44, 19756-19763. [CrossRef]

19. Jokar, M.; Darvishi, S.; Torkaman, R.; Kharaziha, M.; Karbasi, M. Corrosion and bioactivity evaluation of nanocomposite PCL-forsterite coating applied on 316L stainless steel. Surf. Coat. Technol. 2016, 307, 324-331. [CrossRef]

20. Iqbal, N.; Iqbal, S.; Iqbal, T.; Bakhsheshi-Rad, H.R.; Alsakkaf, A.; Kamil, A.; Abdul kadir, M.R.; Idris, M.H.; Raghav, H.B. Zinc-doped hydroxyapatite-Zeolite/polycaprolactone composites coating on magnesium substrate for enhancing in-vitro corrosion and antibacterial performance. Trans. Nonferrous Met. Soc. China 2020, 30, 123-133. [CrossRef]

21. Azarudeen, R.S.; Hassan, M.N.; Yassin, M.A.; Thirumarimurugan, M.; Muthukumarasamy, N.; Velauthapillai, D.; Mustafa, K. 3D printable Polycaprolactone-gelatin blends characterized for in vitro osteogenic potency. React. Funct. Polym. 2020, 146, 104445. [CrossRef]

22. Sadeghzade, S.; Emadi, R.; Tavangarian, F.; Doostmohammadi, A. In vitro evaluation of diopside/baghdadite bioceramic scaffolds modified by polycaprolactone fumarate polymer coating. Mater. Sci. Eng. C 2020, 106, 110176. [CrossRef] [PubMed]

23. Bakshi, P.S.; Selvakumar, D.; Kadirvelu, K.; Kumar, N.S. Chitosan as an environment friendly biomaterial—A review on recent modifications and applications. Int. J. Biol. Macromol. 2019. [CrossRef] [PubMed]

24. Palla-Rubio, B.; Araújo-Gomes, N.; Fernández-Gutiérrez, M.; Rojo, L.; Suay, J.; Gurruchaga, M.; Goñi, I. Synthesis and characterization of silica-chitosan hybrid materials as antibacterial coatings for titanium implants. Carbohydr. Polym. 2019, 203, 331-341. [CrossRef] [PubMed]

25. Jung, J.; Li, L.; Yeh, C.-K.; Ren, X.; Sun, Y. Amphiphilic quaternary ammonium chitosan/sodium alginate multilayer coatings kill fungal cells and inhibit fungal biofilm on dental biomaterials. Mater. Sci. Eng. C 2019, 104, 109961. [CrossRef] 
26. Ramos Avilez,H.V.; Castilla Casadiego, D.A.; Vega Avila, A.L.; Perales Perez, O.J.; Almodovar, J. 11-Production of chitosan coatings on metal and ceramic biomaterials. In Chitosan Based Biomaterials Volume 1; Jennings, J., Bumgardner, J., Eds.; Woodhead Publishing: Sawston, UK, 2017; pp. 255-293.

27. Gao, F.; Hu, Y.; Gong, Z.; Liu, T.; Gong, T.; Liu, S.; Zhang, C.; Quan, L.; Kaveendran, B.; Pan, C. Fabrication of chitosan/heparinized graphene oxide multilayer coating to improve corrosion resistance and biocompatibility of magnesium alloys. Mater. Sci. Eng. C 2019, 104, 109947. [CrossRef]

28. Soleymani, F.; Emadi, R.; Sadeghzade, S.; Tavangarian, F. Applying baghdadite/PCL/chitosan nanocomposite coating on AZ91 magnesium alloy to improve corrosion behavior, bioactivity, and biodegradability. Coatings 2019, 9, 789. [CrossRef]

29. Sadeghzade, S.; Shamoradi, F.; Emadi, R.; Tavangarian, F. Fabrication and characterization of baghdadite nanostructured scaffolds by space holder method. J. Mech. Behav. Biomed. Mater. 2017, 68, 1-7. [CrossRef]

30. Zhang, Y.; Yan, C. Development of anodic film on Mg alloy AZ91D. Surf. Coat. Technol. 2006, 201, $2381-2386$. [CrossRef]

31. Sadeghzade, S.; Emadi, R.; Labbaf, S. Hardystonite-diopside nanocomposite scaffolds for bone tissue engineering applications. Mater. Chem. Phys. 2017, 202, 95-103. [CrossRef]

32. Kokubo, T.; Takadama, H. How useful is SBF in predicting in vivo bone bioactivity? Biomaterials 2006, 27, 2907-2915. [CrossRef] [PubMed]

33. Sadeghzade, S.; Emadi, R.; Tavangarian, F.; Naderi, M. Fabrication and evaluation of silica-based ceramic scaffolds for hard tissue engineering applications. Mater. Sci. Eng. C 2017, 71, 431-438. [CrossRef] [PubMed]

34. Williamson, G.K.; Hall, W.H. X-ray line broadening from filed aluminium and wolfram. Acta Metall. 1953, 1, 22-31. [CrossRef]

35. Razavi, M.; Fathi, M.; Savabi, O.; Vashaee, D.; Tayebi, L. In vitro study of nanostructured diopside coating on Mg alloy orthopedic implants. Mater. Sci. Eng. C 2014, 41, 168-177. [CrossRef]

36. Gnedenkov, S.V.; Sinebryukhov, S.L.; Mashtalyar, D.V.; Nadaraia, K.V.; Kiryukhin, D.P.; Kichigina, G.A.; Kushch, P.P.; Buznik, V.M. Composite coatings formed on the PEO-layers with the use of solutions of tetrafluoroethylene telomers. Surf. Coat. Technol. 2018, 346, 53-62. [CrossRef]

37. Roohani-Esfahani, S.I.; Dunstan, C.R.; Davies, B.; Pearce, S.; Williams, R.; Zreiqat, H. Repairing a critical-sized bone defect with highly porous modified and unmodified baghdadite scaffolds. Acta Biomater. 2012, 8, 4162-4172. [CrossRef]

38. Ramaswamy, Y.; Wu, C.; Van Hummel, A.; Combes, V.; Grau, G.; Zreiqat, H. The responses of osteoblasts, osteoclasts and endothelial cells to zirconium modified calcium-silicate-based ceramic. Biomaterials 2008, 29, 4392-4402. [CrossRef]

39. Sadeghzade, S.; Emadi, R.; Labbaf, S. Formation mechanism of nano-hardystonite powder prepared by mechanochemical synthesis. Adv. Powder Technol. 2016, 27, 2238-2244. [CrossRef]

40. Sadeghzade, S.; Emadi, R.; Tavangarian, F. Combustion assisted synthesis of hardystonite nanopowder. Ceram. Int. 2016, 42, 14656-14660. [CrossRef]

41. Sadeghzade, S.; Emadi, R.; Ghomi, H. Mechanical alloying synthesis of forsterite-diopside nanocomposite powder for using in tissue engineering. Ceram. Silikáty 2015, 59, 1-5.

42. Sadeghzade, S.; Emadi, R.; Ahmadi, T.; Tavangarian, F. Synthesis, characterization and strengthening mechanism of modified and unmodified porous diopside/baghdadite scaffolds. Mater. Chem. Phys. 2019, 228, 89-97. [CrossRef]

43. Sadeghzade, S.; Emadi, R. Improving the mechanical and bioactivity of hydroxyapatite porous scaffold ceramic with diopside/forstrite ceramic coating. Nanomed. J. 2019, 6, 50-54.

(C) 2020 by the authors. Licensee MDPI, Basel, Switzerland. This article is an open access article distributed under the terms and conditions of the Creative Commons Attribution (CC BY) license (http://creativecommons.org/licenses/by/4.0/). 